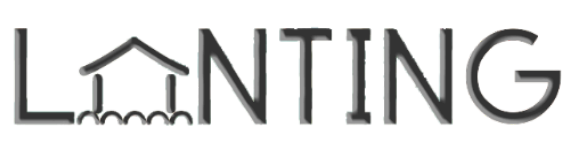

\title{
LEARNING CENTER UNIVERSITAS LAMBUNG MANGKURAT DI BANJARBARU
}

\author{
Rizki Mailindasari \\ Program Studi Teknik Arsitektur Fakultas Teknik Universitas Lambung Mangkurat \\ mailinda2907@gmail.com \\ Prima Widia Wastuty \\ Program Studi Teknik Arsitektur Fakultas Teknik Universitas Lambung Mangkurat \\ primawidiawastuty@ulm.ac.id
}

\begin{abstract}
ABSTRAK
Perkembangan pesat teknologi dan informasi belakangan ini mempengaruhi cara kita mengerjakan sesuatu. Seiring dengan adanya teknologi komunikasi jarak jauh menjadikan pekerjaan dapat dilakukan dengan jarak jauh (teleworking). Hal tersebut menjadi sebab berubahnya cara belajar mahasiswa belakangan ini. Mahasiswa dapat belajar dimana saja Akibatnya adalah menurunnya budaya akademik di area kampus karena mahasiswa memilih untuk melakukan kegiatan belajar di luar kampus. Namun, Universitas Lambung Mangkurat sebagai perguruang tinggi belum dapat mewadahi secara maksimal kegiatan belajar mahasiswa di luar waktu kuliah. Oleh karena itu, Learning Center diperlukan sebagai penunjang pembelajaran dan budaya akademik di area kampus. Metode arsitektur pemrograman (architecture programming) dipilih sebagai metode perancangan. Metode arsitektur pemrograman dibagi ke dalam Lima proses yaitu goals, facts, concept, needs, dan problem. Metode pemrograman arsitektur memperhatikan secara seksama pada permasalahan dalam perancangan. Generasi Z merupakan generasi dominan pada perguruan tinggi saat ini sehingga tren belajar Generasi Z menjadi acuan dalam perancangan. Konsep Flexible Learning merupakan konsep Learning Center yang mewadahi belajar fleksibel mahasiswa. Flexible Learning sesuai dengan tren belajar generasi $Z$ yang memiliki fleksibilitas pada ruang belajar, media belajar, waktu belajar, dan gaya belajar.
\end{abstract}

Kata kunci: Learning Center, Generasi Z, Flexible Learning.

\begin{abstract}
The rapid development of technology and information lately affects the way we do things. Along with the existence of remote communication technology makes the work can be done remotely (teleworking). This is the reason for the changing way students learn lately. Students can study anywhere As a result is the decline of academic culture in the campus area because students choose to do learning activities off campus. However, Lambung Mangkurat University as a college has not been able to accommodate the maximum student learning activities outside of college time. Therefore, the Learning Center is needed as a support for learning and academic culture in the campus area. The architecture programming method was chosen as the design method. Programming architecture method is divided into five processes namely goals, facts, concept, needs, and problems. Architectural programming methods pay close attention to the problems in design. Generation $Z$ is the dominant generation in universities today so the trend of learning Generation Z becomes a reference in design. Flexible Learning concept is a Learning Center concept that accommodates students' flexible learning. Flexible Learning is in accordance with generation Z learning trends that have flexibility in learning space, learning media, learning time, and learning style.
\end{abstract}

Keywords : Learning Center, Gen Z, Flexible Learning 


\section{PENDAHULUAN}

Cara kita bekerja sekarang sangat dipengaruhi oleh kemajuan dan perkembangan teknologi yang sangat pesat akhir-akhir ini. Seiring dengan ditemukannya perangkat telepon, telepon genggam, dan internet menjadikan cara kita bekerja mulai berubah. Teknologi tersebut mempermudah kita dalam menyelesaikan pekerjaan. Teknologi tersebut menjadikan pekerjaan dapat dilakukan dengan kondisi jarak jauh (teleworking). Pekerjaan jarak jauh tidak mengharuskan kita hadir dalam suatu ruang tertentu untuk mengerjakan sesuatu. Seperti mengumpulkan tugas kuliah yang dapat dilakukan melalui surat elektronik dan lainnya. Pengumpulan tugas kuliah tidak lagi mengharuskan mahasiswa untuk bertemu langsung dengan dosen, akan tetapi dapat dilakukan dengan cara mengirim pesan elektronik ke alamat elektronik milik dosen dengan waktu yang singkat.

Beberapa pekerjaan yang dapat dilakukan dengan jarak jauh menjadikan pekerjaan dapat diselesaikan dimana saja. Rumah, kafe, ataupun ruang kerja bersama menjadi tren ruang kerja yang diminati belakangan ini oleh generasi $Z$. Fenomena tersebut salah satunya terjadi pada mahasiswa. Mahasiswa saat ini juga senang untuk mengerjakan tugas di cafe, rumah, atau ruang kerja bersama. Ruang belajar dengan suasana yang menyenangkan dan bebas menjadi alasan mereka memilih bekerja di cafe, rumah, atau ruang kerja bersama tersebut.

Universitas Lambung Mangkurat merupakan universitas tertua di Kalimantan. Universitas Lambung Mangkurat memiliki kampus di 5 lokasi (Banjarmasin; kampus Universitas Lambung Mangkurat Banjarmasin di Jalan Hasan Basri, kampus fakultas kedokteran di Jalan Veteran, Banjarbaru: kampus Universitas Lambung Mangkurat Banjarbaru di Jalan Ahmad Yani, kampus fakultas Keguruan dan IImu Pendidikan, dan kampus fakultas Pendidikan Olahraga ). Kampus Universitas Lambung Mangkurat Banjarbaru yang terletak di Jalan Ahmad Yani Banjarbaru merupakan salah satu kampus utama Universitas
Lambung Mangkurat. Mahasiswa Universitas Lambung Mangkurat di Banjarbaru tidak terlepas dari pengaruh tren belajar generasi $\mathrm{Z}$ sekarang ini. Mahasiswa Universitas Lambung Mangkurat di Banjarbaru juga senang bekerja di luar kampus seperti di kafe. Mereka memilih melakukan pekerjaan di kafe karena suasana nyaman dan internet gratis yang ditawarkan oleh cafe. Kafe juga membuka jam pelayanan pada malam hari dimana mahasiswa biasanya aktif mengerjakan tugas di jam-jam tersebut.

Universitas Lambung Mangkurat sebagai perguruan tinggi berusaha menjalankan perannya secara maksimal. Undang-Undang nomor 12 tahun 2012 menyebutkan tanggung jawab sivitas akademika perguruan tinggi untuk membangun budaya akademik di area kampus. Akan tetapi, tren melakukan pekerjaan yang diikuti mahasiswa saat ini plum dapat terwadahi dengan baik di kampus Universitas Lambung Mangkurat Banjarbaru. Kampus Universitas Lambung Mangkurat Banjarbaru belum dapat mewadahi secara maksimal kegiatan belajar mahasiswa di luar jam kuliah di area kampus. Hal tersebut menyebabkan banyak mahasiswa memilih untuk belajar mandiri dan terstruktur di luar area kampus seperti di kafe dan rumah. Oleh karena itu, perlu adanya ruang belajar bagi mahasiswa di area kampus agar terbangunnya kembali budaya akademik di area kampus.

Pusat pembelajaran atau Learning Center merupakan ruang belajar yang mewadahi mahasiswa maupun sivitas akademika dalam melakukan kegiatan belajar dan mengembangkan pendidikan. Learning Center menawarkan fasilitasfasilitas yang dapat memenuhi kebutuhan sivitas akademika. Learning Center dapat menjadi sarana yang melayani selama 24 jam dalam sehari yang dilengkapi berbagai penunjang kegiatan belajar seperti; printer, scanner, koneksi internet cepat, dan lain- lain. Learning Center menyediakan pilihan ruang belajar beragam dan kondusif bagi mahasiswa. Mulai dari ruang belajar komunal, ruang belajar bersama, ruang belajar tertutup, sampai bimbingan untuk pengembangan 
akademik mahasiswa. Learning Center juga menyediakan fasilitas pengembangan pembelajaran bagi kampus atau tenaga pendidik.

Learning Center diperlukan Universitas Lambung Mangkurat sebagai sarana penunjang pembelajaran dan budaya akademik di area kampus. Learning Center sebagai ruang yang mewadahi belajar secara kondusif bagi mahasiswa Universitas Lambung Mangkurat di Banjarbaru. Learning Center dapat menarik kembali minat mahasiswa yang selama ini mengerjakan tugas kuliah di luar kampus untuk kembali di kampus yang selama ini menurun. Learning Center juga dapat menjadi sarana pengembangan pembelajaran bersama untuk seluruh sivitas akademika kampus Universitas Lambung Mangkurat di Banjarbaru.

\section{PERMASALAHAN}

Bagaimana rancangan Learning Center Universitas Lambung Mangkurat yang mewadahi kegiatan belajar yang sesuai dengan tren belajar saat ini?

\section{TINJAUAN PUSTAKA}

\section{A. Pengertian Learning Center}

Learning Center atau Pusat Pembelajaran adalah gabungan dari empat layanan. Empat layanan tersebut yaitu; perpustakaan, layanan multimedia (audio visual), kegiatan belajar non tradisional (termasuk bimbingan), dan layanan pengembangan pelajaran (yaitu layanan dalam pengembangan strategi mengajar, materi kuliah, dan mata kuliah baru untuk fakultas). (Peterson dalam Truschel, dkk, 2009)

Learning Center disebut juga sebagai Learning Common. Learning Common ruang fisik ataupun virtual yang kondusif untuk pembelajaran dua arah, percobaan, dan pembelajaran kolaboratif (Pokorny, 2013). Learning Common berevolusi dari kombinasi antara perpustakaan dan laboratorium komputer menjadi ruang pembelajaran dengan layanan penuh, ruang penelitian, dan ruang proyek. Konsep tradisional Common yang berarti sebuah tempat sosial bagi masyarakat mulai dari tempat ternak merumput, panggung festival, atau tempat pertemuan ini digaris bawahi sebagai dasar dari sebuah Learning Common Modern. Learning Common merupakan lingkungan fleksibel dibangun untuk mewadahi berbagai macam kegiatan pembelajaran. (Educause, 2011).

Learning Center, Learning Common, atau Pusat Pembelajaraan menggabungkan layanan perpustakaan, multimedia, kegiatan belajar non tradisional, dan pengembangan pembelajaran untuk fakultas. Learning Center mewadahi kegiatan pembelajaran yang mendukung pengembangan pembelajaran bagi mahasiswa dan fakultas atau universitas.

\section{B. Aktivitas di dalam Learning Center}

Learning Center menyediakan fungsi pelayanan bagi mahasiswa, dosen, maupun pengunjung. Layanan yang disediakan oleh Learning Center satu dengan lainnya berbeda. Layanan yang disediakan Learning Center tergantung dari tujuan tiap institusi pengelolanya. Learning Center atau Pusat Pembelajaran adalah gabungan dari empat layanan. Empat layanan tersebut yaitu; perpustakaan, layanan multimedia (audio visual), kegiatan belajar non tradisional (termasuk bimbingan), dan layanan pengembangan pelajaran (yaitu layanan dalam pengembangan strategi mengajar, materi kuliah, dan mata kuliah baru untuk fakultas). (Peterson dalam Truschel, dkk, 2009).

Multimedia diambil dari kata multi dan media. Multi berarti banyak dan media berarti media atau perantara. Multimedia adalah gabungan dari beberapa unsur yaitu teks, grafik, suara, video dan animasi yang menghasilkan presentasi yang menakjubkan. Multimedia juga mempunyai komunikasi interaktif yang tinggi. Bagi pengguna komputer, multimedia dapat diartikan sebagai informasi komputer yang dapat disajikan melalui audio atau video, teks, grafik dan animasi. Multimedia secara umum 
merupakan kombinasi tiga elemen, yaitu suara, gambar dan teks.

Layanan multimedia berarti layanan yang berkaitan dengan teks, grafik, suara, video dan animasi. Layanan multimedia termasuk di dalamnya yaitu; koleksi CD (Compact Disk), CD ROM ( Compact Disk Read Only Memory), DVD, dan kaset.

Belajar nontradisional diartikan

kegiatan belajar yang dilakukan diluar dari belajar tradisional. Belajar tradisional merupakan metode menerima pelajaran secara langsung dengan tatap muka yang umumnya terjadi antara murid dan guru. Belajar tradisional umum dilaksanakan di ruang kelas. Sedangkan, belajar nontradisional adalah belajar aktif yang dilakukan dua arah seperti diskusi kelompok dan lainnya.

Layanan pengembagan untuk fakultas adalah layanan pengembangan strategi mengajar, materi kuliah, dan mata kuliah.

Beberapa contoh layanan yang disediakan Learning Center seperti dibawah (Thorne, dkk, 2013):
a.) Layanan teknologi informasi:
menawarkan bantuan tentang
software maupun hardware pada gadget pribadi

b.) Layanan dan dukungan keberhasilan akademik: menawarkan layanan termasuk di dalamnya layanan tulis, program kursus, bantuan untuk mahasiswa yang mengalami kesulitan akademik, dan bimbingan akademik, semua hal tersebut secara spesifik untuk mendukung kegiatan akademik.

c.) Layanan penelitian dan referensi: bertujuan untuk membantu mahasiswa dalam pekerjaan akademik mereka. Layanan ini termasuk dari meja informasi, meja referensi, bantuan penelitian, dan knowledge 6ar. Layanan ini tidak berbeda jauh dari layanan perpustakaan akademik pada umumnya. Contohnya; pustakawan keliling yang menyediakan kebutuhan pengguna di titik titik tertentu. Layanan penelitian tambahan termasuk pusat data dan teknologi pengkoleksi data, analisis, dan sistem visualisasi dan pelatihan oleh para staf.

d.) Layanan meja pustaka: layanan ini sering mulai menggunakan bantuan teknologi atau mesin untuk membantu pengguna mencari pustaka yang mereka cari.

e.) Sosialisasi literasi: learning center mengadakan kelas atau ruang untuk pengajaran berbagai informasi dan workshop literasi.

f.) Layanan mahasiswa: Tidak seperti layanan akademik mahasiswa pada umumnya, layanan ini menyediakan program kesehatan, konseling, layanan berkebutuhan khusus, layanan karir, layanan mahasiswa internasional, layanan mahasiswa baru.

g.) Layanan fakultas: Secara garis besar

bertujuan mendukung fakultas dalam hal pengembangan pengajaran, kelas, kelas online, kolaborasi dan learning resource center.

h.) Hospitality service: termasuk di dalamnya layanan makan dan minum, seperti kafe ataupun vending machine.

i.) Layananadministrasi: Di dalamnya terdapat layanan registrasi, layanan keuangan siswa, penerimaan mahasiswa, studi sarjana lanjutan, kantor alumni.

j.) Toko buku: Layanan ini tidak sering ditemui, tetapi layanan ini menjual barang seperti buku dan alat tulis.

k.) Layanan komunitas: Layanan ini melayanai minat dari komunitas, dapat berupa lokakarya, penelitian, pusat inovasi dan lain-lain.

\section{Pelaku di dalam Learning Center}

Learning Cen/er ditujukan sebagai wadah untuk pengembangan akademik mashasiswa maupun sivitas akademika, Di samping itu Learning Center juga dibuka untuk masyarakat umum ataupun pengunjung dari institusi lain. Learning Center sering mengadakan acara terbuka yang dapat dikunjungi oleh sivitas akademika dan masyarakat umum. (Thorne, dkk, 2013; Educause, 2011) 


\section{Fasilitas di dalam Learning Center}

Fasilitas yang tersedia di Learning Center satu dengan lainnya dapat berbeda, Akan tetapi, hal yang utama adalah ruang belajar untuk mahasiswa. Pusat Pembelajaran sering dirancang sebagai 'third place'-sebuah ruang yang bukan rumah ataupun tempat kerja. Pusat Pembelajaran fokus pada ruang kolaborasi dan fleksibel yang berpusat pada mahasiswa. Contohnya pada ruang utama yang umumnya luas dan dilengkapi furniture informal yang dapat dipindah. Furniture tersebut memberikan pengguna kebebasan untuk melakukan pekerjaan kelompok atau belajar mandiri. Ruang lain seperti ruang rapat, area menulis dan bimbingan, kantor bimbingan, dan ruang sosial dengan fasilitas makan dan minum. (Thorne, dkk, 2013)

Pusat Pembelajaran modern menawarkan hal lebih dari teknologi canggih, ruang belajar, ataupun layanan bagi mahasiswa. Nilai penting dari Pusat Pembelajaran adalah jalinan kolaborasi sosial antara sumber dayanya yang menjadikan ruang fisik, peralatan digital, dan dukungan ahli di dalamnya menjadi lebih baik (Beagle dalam Thorne, dkk, 2013)

Beberapa teknologi yang terdapat di Pusat Pembelajaran (Thorne, dkk):

a.) Ruang kerja dengan komputer: hampir seluruh Learning Center memiliki ruang komputer

b.) Laptop dan atau tablet: learning center menyediakan tablet atau laptop untuk dipinjamkan kepada mahasiswa.

c.) Wi-fi

d.) Printing

e.) Scanners

f.) Proyektor

g.) Monitor $L C D$

h.) Peralatan konferensi jarak jauh

\section{E. Tinjauan Tren Belajar Saat Ini Pengertian Tren Belajar}

Trend berarti suatu gerakan atau kecenderungan naik atau turun dalam jangka panjang yang diperoleh dari rata-rata perubahan dari waktu ke waktu, rata-rata perubahan tersebut bisa bertambah bisa berkurang. Jika rata-rata perubahan bertambah, maka disebut tren positif atau mempunyai kecenderungan naik. Sebaliknya, jika rata-rata perubahan berkurang disebut tren negatif mempunyai kecenderungan menurun (Maryati, 2010: 129 dalam Ratnasari, 2018)

Menurut Winkel (1996: 53) dalam Afandi, dkk (2013) belajar adalah suatu aktivitas mental atau psikis, yang berlangsung dalam interaksi aktif dengan lingkungan yang menghasilkan perubahan- perubahan dalam pengetahuan, pemahaman, keterampilan, dan nilai sikap.

Tren belajar berarti suatu kecenderungan dalam aktivitas belajar yang menghasilkan perubahan-perubahan dalam pengetahuan, pemahaman, keterampilan, dan nilai sikap. Dalam konteks mahasiswa belajar dapat diartikan sebagai aktivitas mengerjakan tugas, proyek, penelitian, dan lain-lain.

Generasi Z merupakan generasi yang mendominasi dunia pendidikan sekarang ini, sehingga rancangan Learning Center ini menjadikan karakter dan tren belajar generasi $Z$ sebagai acuan dalam perancangan.

\section{F. Trend Belajar Generasi Z}

Tren belajar generasi $Z$ diuraikan sebagai berikut:

a.) Fasilitas belajar

Generasi Z merupakan generasi digital. Generasi Z sangat akrab dengan media digital dan generasi $Z$ hampir tidak bisa lepas dari koneksi internet. Sehingga, fasilitas wifi menjadi penting bagi generasi $Z$. Generasi Z menyukai melakukan pekerjaan atau belajar sambil mengkonsumsi minuman dan makanan. Belajar sambil

mengkonsumsi minuman lebih senang dilakukan generasi Z karena lebih mudah untuk dilakukan. 
b.) Ruang belajar

Generasi Z dapat melakukan pekerjaan termasuk belajar dimana saja. Salah satu tempat yang menjadi favorit generasi $Z$ adalah kafe. Mereka memilih untuk duduk di pinggir-pinggir jendela yang mengarah keluar ruangan. Apabila berkelompok mereka lebih memilih area tengah ruangan. Mereka yang datang sendiri lebih memilih untuk duduk di pojok-pojok dari ruangan kafe.

Suasana cafe yang lebih bising tidak menghalangi generasi $Z$ untuk belajar. Kebisingan tersebut malah dapat membantu mereka dalam belajar. Belajar di kafe juga membuat mereka dapat mengamati area di sekitar mereka yang dinamis.

Meskipun kafe menjadi salah satu tempat favorit bagi generasi Z untuk belajar. Dalam belajar generasi $Z$ lebih menyukai untuk belajar mandiri. Akan tetapi, generasi $Z$ juga menyadari pentingnya belajar bersama atau kolaborasi.

c) Media belajar

Media belajar bagi generasi $Z$ sangat fleksibel. Generasi $Z$ yang merupakan generasi digital lebih sering belajar dari media elektronik atau internet. Generasi Z menyukai media belajar visual yang salah satunya berupa video. Hal tersebut juga membuat mereka jarang menjadikan media fisik seperti buku sebagai referensi pembelajaran.

d.) Waktu belajar:

Waktu aktif atau produktif generasi Z sedikit berbeda dari generasi sebelumnya. Generasi Z seringkali mulai datang untuk belajar di kafe pada sore hari. Mahasiswa generasi $Z$ juga lebih aktif dan produktif dalam belajar di malam hari. Seperti studi pada beberapa contoh Learning Cenfer bahwa banyak mahasiswa mulai datang pada pukul 9 malam dan pulang pada pukul 2 dini hari.

e.) Gaya belajar:

Generasi Z senang melakukan pekerjaan dalam posisi yang nyaman. Mulai dari posisi duduk, berselonjor, dan lain-lain. Generasi Z senang melakukan banyak pekerjaan pada satu waktu. Seperti menggunakan alat pemutar musik, komputer, dan telepon genggam pada saat yang bersamaan. Generasi Z senang belajar di kafe karena dapat melakukan hal lain seperti mengamati suasana kafe dan orang-orang yang beraktivitas di dalamnya.

\section{G. Ringkasan Tren Belajar dan Karakter Generasi Z pada Arsitektur}

Berdasarkan tinjauan literatur mengenai karakter dan tren belajar generasi $Z$ dapat dirangkum beberapa poin yang berkaitan dengan arsitektur. Karakter generasi $Z$ yang sangat dekat dengan teknologi mengharuskan arsitektur atau rancangan mengikuti tren digital yang berkembang saat ini. Tren digital dan media sosial yang dialami generasi Z menjadikan mereka cenderung tidak aktif bergerak ataupun bersosialisasi. Rancangan arsitektur sebaiknya dirancang agar generasi $Z$ dapat aktif bergerak ataupun bersosialisasi dengan rancangan-rancangan yang menarik bagi generasi $Z$.

Generasi Z merupakan multitasker yang menyukai hal cepat dan tidak bertele-tele. Hal tersebut perlu diperhatikan pada sirkulasi rancangan yang mudah diakses, tetapi tidak menyebabkan mereka tidak aktif. Kemampuan multitasker generasi $Z$ juga menjadikan mereka dapat belajar sambil melakukan berbagai macam hal seperti berbicara atau menonton hal lain. Dengan alasan tersebut, ruang belajar dapat dirancang bersama dengan sosial pada satu ruang. Karena, hal tersebut tidak terlalu berpengaruh malah menjadi hal positif bagi mereka.

Generasi Z merupakan generasi visual yang sangat menyukai informasi-informasi dalam bentuk visual. Sehingga, visual dari rancangan sangat diperhatikan dan informasi atau penanda lebih baik dirancang dalam bentuk visual. Generasi Z juga sangat senang untuk membuat sesuatu ditambah dengan kreativitas mereka yang luas akibat berkembangnya teknologi dan informasi. 
Hal tersebut dapat diwadahi pada rancangan learning Center ini sebagai proses belajar.

Generasi Z adalah generasi yang mencintai lingkungan sehingga rancangan bangunan ramah lingkungan menjadi pilihan baik bagi rancangan ini.

Tren belajar generasi $Z$ sebagian besar dapat dirangkum dengan kata fieksibel. Pertama, generasi $Z$ sangat membutuhkan koneksi internet sehingga witi sangat diperlukan. Kedua, ruang belajar, bagi generasi $Z$ ruang belajar dapat dimana saja asalkan mereka merasa nyaman. Yang perlu diperhatikan adlah generasi $Z$ suka mengamati sekitar saat belajar. Mereka yang belajar sendiri juga lebih menyenangi pojok-pojok ruangan yang lebih privat, sedangkan mereka yang belajar berkelompok tidak masalah untuk belajar di tengah ruang komunal. Ketiga, media belajar generasi $Z$ juga fleksibel karena berkembangnya teknologi sehingga tersedia berbagai macam jenis informasi. Generasi Z menyukai media belajar digital maupun cetak. Keempat, waktu belajar generasi Z sangat fleksibel seiring dengan ruang belajar mereka. Terakhir, generasi $Z$ menyukai gaya belajar yang bermacam-macam mulai dari duduk, rebahan, berselonjor, sambil makan atau minum.

\section{METODOLOGI}

Metode Programming menjadi metode yang tepat untuk menyelesaikan permasalahan pada rancangan ini. Menurut William Pena (2001) programming dan desain merupakan proses yang berbeda. Programming merupakan proses yang bertujuan pada pernyataan permasalahan arsitektural dan hal-hal yang perlu diperhatikan untuk mengajukan sebuah solusi dari masalah arsitektural. Proses programming terdiri dari lima tahap proses dasar. Dalam bahasa lain programming adalah proses pencarian masalah, sedangkan desain adalah proses penyelesaian masalah.

Lima tahap yang dilakukan dalam proses programming adalah menentukan tujuan (Goals), mengumpulkan dan menganalisis fakta (Facts), mengungkapkan dan menguji konsep
(Concepts), menentukan kebutuhan (Needs), dan menyatakan permasalahan (Problem). Hal- hal tersebut perlu dilakukan untuk menemukan masalah sebenarnya yang menjadi pertimbangan desain.

Berdasarkan permasalahan arsitektural yaitu Learning Center yang mewadahi pembelajaran sesuai dengan tren yang berkembang saat ini. Metode perancangan yang digunakan adalah metode programming dan berdasarkan pada tren generasi yang mendominasi dunia pendidikan tinggi sekarang. Generasi Z merupakan generasi yang mendominasi dunia pendidikan sekarang ini, sehingga rancangan Learning Center ini menjadikan karakter dan tren belajar generasi $Z$ sebagai acuan dalam perancangan.

\section{PEMBAHASAN}

\section{A. Lokasi Tapak}

Lokasi Learning Center Universitas Lambung Mangkurat terletak di Banjarbaru. Tapak yang dipilih berada dekat dengan Perpustakaan Universitas Lambung Mangkurat yang sudah ada. Lokasi ini dipilih agar mudahnya integrasi layanan perpustakaan dengan Learning Center.

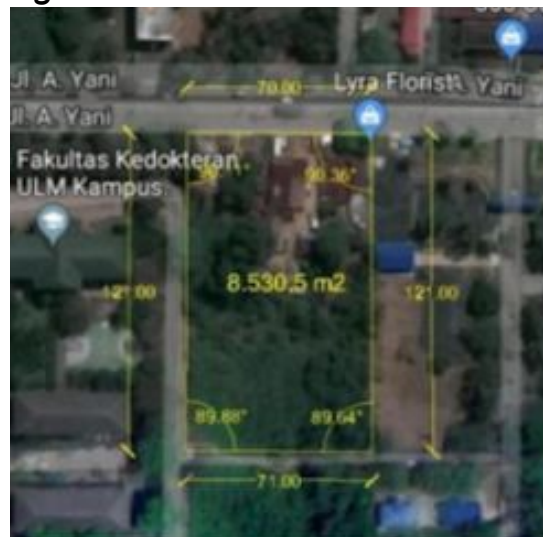

Gambar 1. Tapak

\section{B. Kondisi, Luasan, dan Batasan Tapak}

Menurut Peraturan daerah Banjarbaru tahun 2014 pasal 65, sisi kiri dan kanan sepanjang ruas jalan A. Yani Km. $20-\mathrm{Km}$. 
37 Batas Kota Martapura termasuk ke dalam kawasan perdagangan dan jasa. Kawasan ini memiliki koefisien dasar bangunan sebesar 60-90\%, garis sempadan bangunan dari jalan A. Yani sebesar 25 meter, koefisien lantai bangunan senilai 2,8 , dan koefisien dasar hijau minimal $10 \%$. Perlu adanya sarana parkir, peribadatan, kuliner, dan pejalan kaki di setiap bangunan pada kawasan ini.

Batas tapak sisi Utara adalah jalan Ahmad Yani, sisi Selatan yaitu tanah kosong, sisi Barat adalah fakultas kedokteran Universitas Lambung Mangkurat, dan sisi Timur ialah bamboo square(area kuliner kampus), apotek pendidikan, serta poliklinik Universitas Lambung Mangkurat.

Luas tapak adalah $8.530,5 \mathrm{~m}^{*}$.

\section{Konsep}

1. Konsep Program

Berdasarkan permasalahan arsitektur yaitu Learning Center yang mewadahi pembelajaran sesuai dengan tren yang berkembang sekarang. Metode perancangan yang digunakan adalah metode programming dan berdasarkan pada tren generasi yang mendominasi dunia pendidikan tinggi sekarang. Generasi Z merupakan generasi yang mendominasi dunia pendidikan sekarang ini, sehingga rancangan Learning Center ini menjadikan tren belajar generasi $\mathbf{Z}$ sebagai acuan dalam perancangan. Generasi Z merupakan generasi dengan fleksibilitas tinggi dalam belajar. Fleksibilitas tersebut mulai dari ruang belajar yang fleksibel, media belajar yang fleksibel, waktu belajar yang fleksibel, dan gaya belajar yang fleksibel.

Hal tersebut menjadikan dasar penentuan konsep flexible learning dalam rancangan ini. Flexible learning merupakan konsep yang menawarkan fleksibilitas dalam belajar. Konsep flexible learning dianggap tepat sesuai dengan tren belajar yang dimiliki generasi $Z$ yaitu generasi yang menjadi mayoritas di perguruan tinggi. Learning Center dengan konsep flexible learning menawarkan ruang belajar yang fleksibel, media belajar yang fleksibel, waktu belajar yang fleksibel, dan gaya belajar yang fieksibel dengan berbagai fasilitas pendukung yang mempermudah aktivitas pengguna di dalamnya.

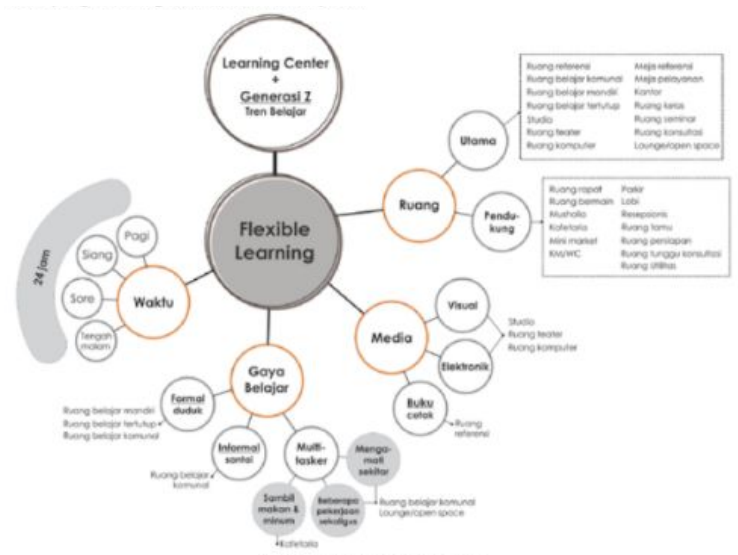

Gambar 2. Konsep Program

Sumber: Penulis (2019)

2. Konsep Desain Rancangan

$$
\text { Konsep Ruang }
$$

Learning Center menjadi wadah bagi aktivitas-aktivitas yang dilakukan pengguna di dalamnya. Aktivitas tersebut tidak statis dan dapat berubah serta dapat merubah ruang di dalamnya. Ruang-ruang di dalam Learning Center diharapkan mewadahi aktivitas-aktivitas fleksibel penggunanya dan ruang-ruang tersebut sendiri menjadi ruang-ruang yang fleksibel. Fleksibilitas di dalamnya mencakup tiga gagasan yaitu kemampuan untuk meluas (expansibility), kemampuan untuk berubah (convertibility), dan kemampuan untuk mewadahi berbagai aktivitas secara bergantian (versatility). Konsep ini kemungkinan terjadinya ruang-ruang baru maupun berubahnya ruang-ruang yang sudah ada menjadi ruang-ruang baru yang mewadahi aktivitas berbeda di dalam Learning Center. 


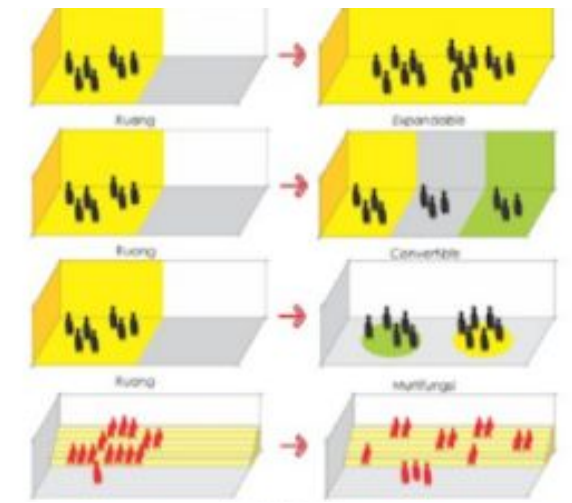

Gambar 3. Fleksibilitas Ruang Sumber: Penulis (2019)

3. Konsep Interior

Area belajar fleksibel mewadahi berbagai gaya belajar mahasiswa. Seperti duduk ataupun berselonjor. Area tersebut dapat berupa amphitheater bagi mahasiswa belajar dengan santai yang tidak langsung bersentuhan langsung dengan lantai.

Interior yang fleksibel juga menjadikan mahasiswa dapat bekerja dimana saja. Seperti kursi dan meja yang flekibel dan dapat dipindah tempatkan.

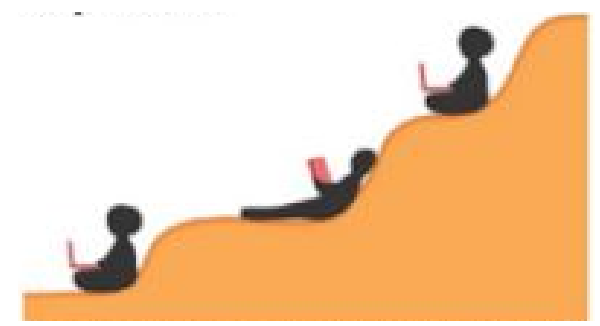

Gambar 4. Konsep Interior Fleksibel Sumber: Penulis (2019)

4. Konsep Fasade

Desain fasade dibuat berirama mengelilingi bangunan sebagai terjemahan dari konsep flexible yaitu

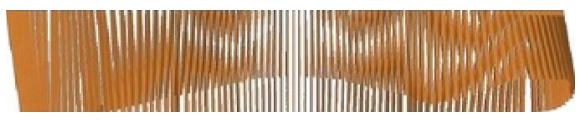

gerak atau flow.

Gambar 5. Tampak Depan Fasade Sumber: Penulis (2019)

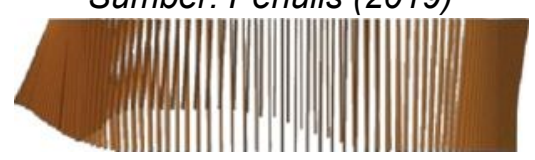

Gambar 8. Tampak Samping Kanan Fasade Sumber: Penulis (2019)

\section{Konsep Elemen Lansekap}

Lansekap dibagi menjadi tiga area. Area servis terletak di belakang bangunan atau sisi Barat tapak, area Selatan tapak sebagai area parkir, dan area Utara tapak menjadi area hijau atau taman. Elemen tempat duduk di tapak mempertimbangkan konsep flexible yang dapat digunakan secara fleksibel untuk belajar. Elemen lansekap dapat digunakan sebagai meja ataupun tempat duduk.

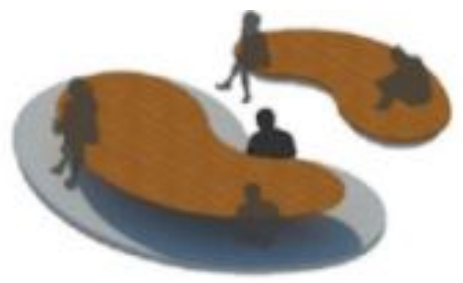

Gambar 7. Elemen Lansekap Sumber: Penulis (2019)

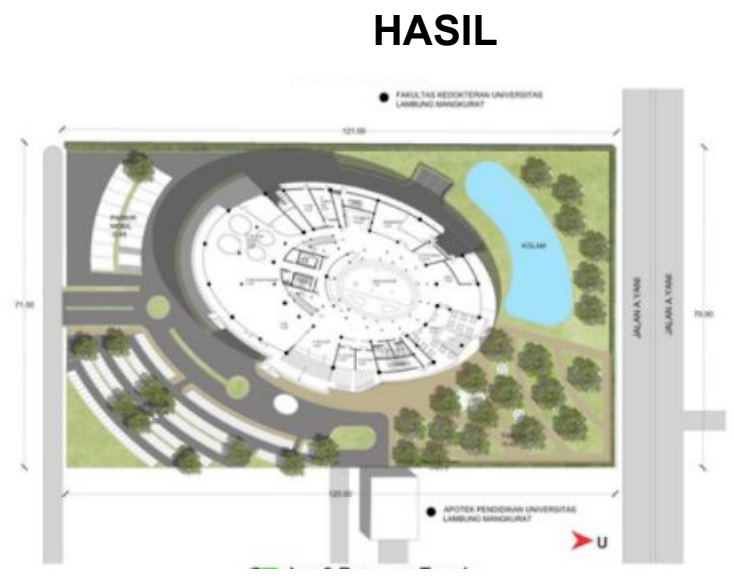

Gambar 8. Rencana Tapak Sumber: Penulis (2019)

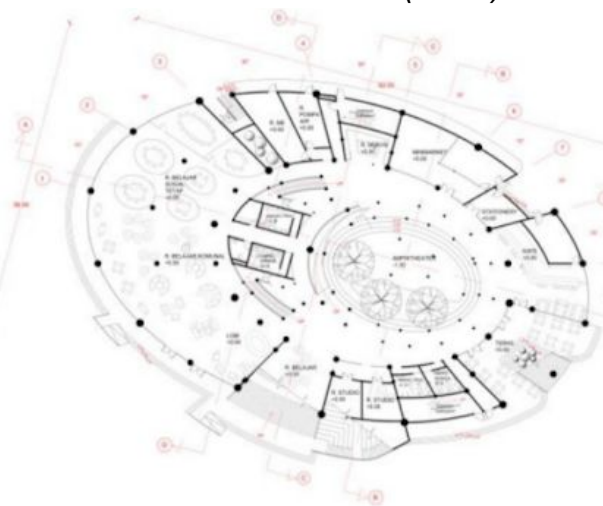

Gambar 9. Denah Lantai 1 Sumber: Penulis (2019) 


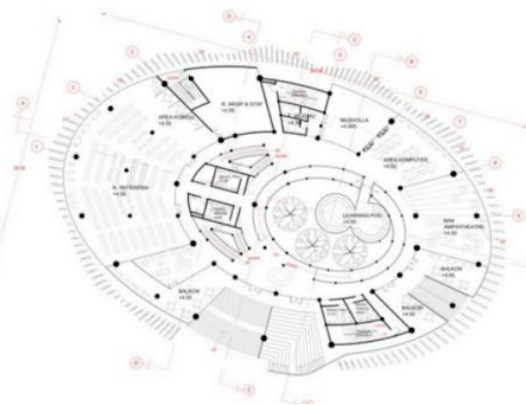

Gambar 10. Denah Lantai 2 Sumber: Penulis (2019)

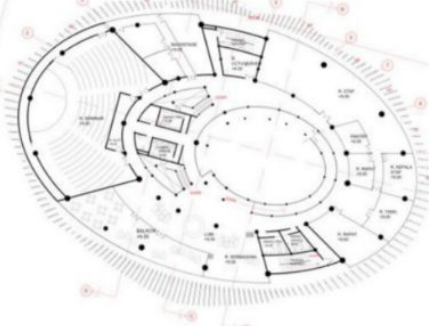

Gambar 11. Denah Lantai 3 Sumber: Penulis (2019)

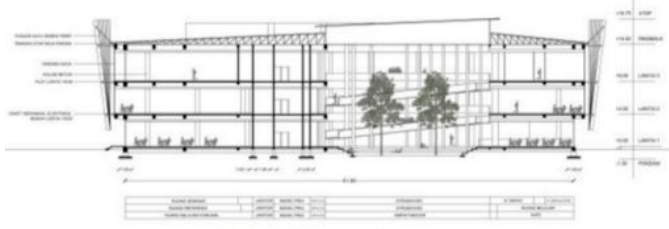

Gambar 12. Potongan Bangunan Sumber: Penulis (2019)

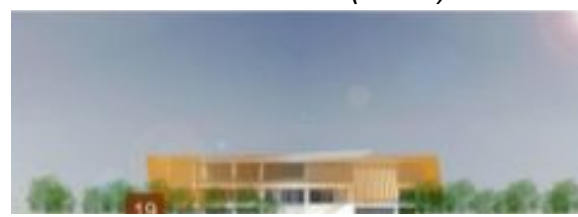

Gambar 13. Tampak Depan Sumber: Penulis (2019)

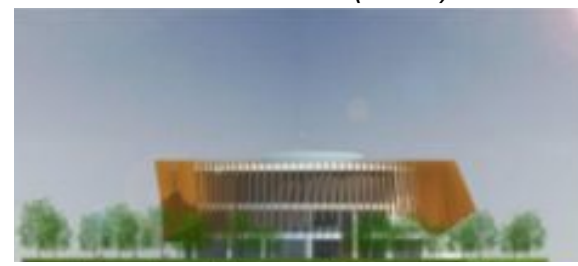

Gambar 14. Tampak Samping Kiri Sumber: Penulis (2019)

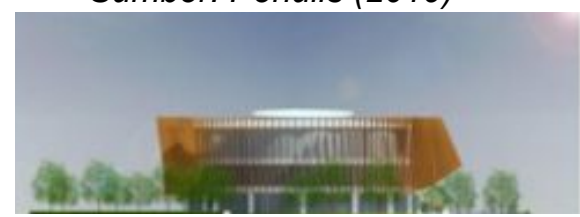

Gambar 15. Tampak Samping Kanan Sumber: Penulis (2019)

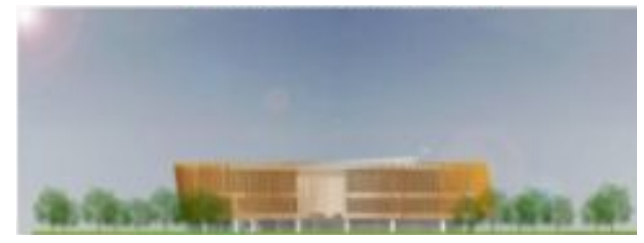

Gambar 16. Tampak Belakang Sumber: Penulis (2019)

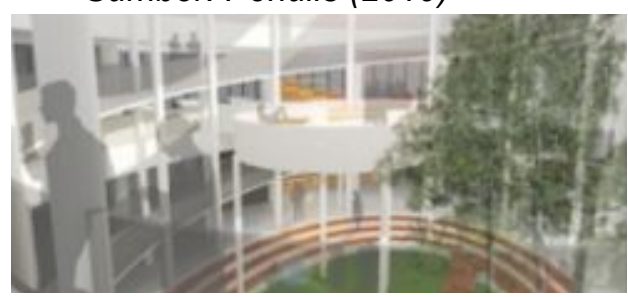

Gambar 17. Perspektif Interior Atrium Sumber: Penulis (2019)

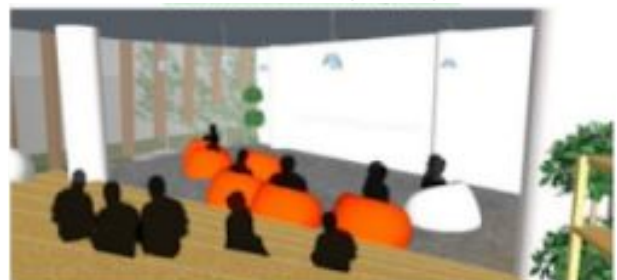

Gambar 18. Ruang Belajar Sumber: Penulis (2019)

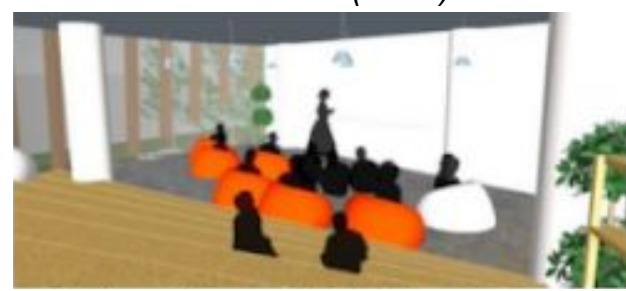

Gambar 19. Ruang Belajar Berubah Fungsi Menjadi Ruang Acara Sumber: Penulis (2019)

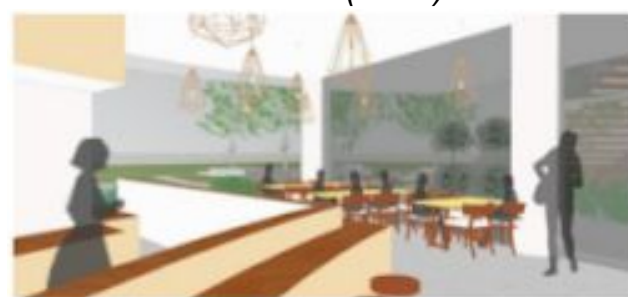

Gambar 20. Perspektif Kafe Sumber: Penulis (2019)

\section{KESIMPULAN}

Learning Center atau Pusat Pembelajaraan menggabungkan layanan perpustakaan, multimedia, kegiatan belajar non tradisional, dan pengembangan pembelajaran untuk fakultas. Learning Center mewadahi kegiatan pembelajaran yang mendukung 
pengembangan pembelajaran bagi mahasiswa dan fakultas atau tenaga pengajar. Learning Center diharapkan menjadi ruang belajar yang sesuai dengan tren belajar saat ini yang dapat mewadahi kegiatan belajar mahasiswa di luar waktu kuliah. Learning Center menjadi ruang belajar yang nyaman dan kondusif sesuai dengan karakter mahasiswa.

Metode penyelesaian masalah arsitektural yang dipilih menggunakan metode arsitektur pemrograman dan berdasarkan pada tren belajar generasi yang mendominasi dunia pendidikan tinggi saat ini. Generasi Z merupakan generasi yang mendominasi dunia pendidikan sekarang ini, sehingga rancangan Learning Center ini menjadikan tren belajar generasi $Z$ sebagai acuan dalam perancangan. Generasi $Z$ merupakan generasi dengan fleksibilitas tinggi dalam belajar. Fleksibilitas tersebut mulai dari ruang belajar yang fleksibel, media belajar yang fleksibel, waktu belajar yang fleksibel, sehingga gaya belajar yang fleksibel.

Hal tersebut menjadikan dasar penentuan konsep flexible learning dalam rancangan ini. Flexible learning merupakan konsep yang menawarkan fleksibilitas dalam belajar. Konsep flexible learning dianggap tepat sesuai dengan tren belajar yang dimiliki generasi $Z$ yaitu generasi yang menjadi mayoritas di perguruan tinggi. Learning Center dengan konsep flexible learning menawarkan ruang belajar yang fleksibel, media belajar yang fleksibel, waktu belajar yang fleksibel, dan gaya belajar yang fleksibel dengan berbagai fasilitas pendukung yang mempermudah aktivitas pengguna di dalamnya. Konsep Flexible Learning diterapkan pada tata ruang pada bangunan, interior bangunan, bentuk fasade bangunan, dan elemen lansekap bangunan.

Learning Center dengan konsep Flexible Learning diharapkan dapat mewadahi kegiatan belajar mahasiswa di luar waktu kuliah yang berada di area kampus. Learning Center dapat meningkatkan budaya akademik di area kampus sebagai salah satu tanggung jawab perguruan tinggi.

\section{DAFTAR PUSTAKA}

\section{Referensi Buku dan Jurnal}

Afandi, dkk. 2013. Model-model Pembelajaran. Semarang: Sultan Agung Press.

Badan Pusat Statistik Kota Banjarbaru. 2018. Kota Banjarbaru dalam Angka.

De Chiara, Joseph, dkk. 1992. Time-Saver Standards for Interior Design and Space Planning. Singapura: McGraw- Hill, Inc.

Educause, 2011. 7 Things You Should Know About the Modern Learning Commons. Universitas Kentucky.

Neufert, Ernst, dan Peter Neufert. 2003. Architects' Data Third Edition. Blackwell Science.

Pena, William, dan Steven A. Parshall. 2001. Problem Seeking. An Architectural Programming Primer 4th Edition. New York: John Wiley \& Sons, Inc.

Ratnasari, Citra Ayu. 2018. Analisis Case Lending Rate Dengan Menggunakan Metode Trend Sebagai Upaya Untuk Memprediksi Laba Pada Pt. Bank Rakyat Indonesia (Persero) Tbk. Universitas Nusantara PGRI Kediri.

Pokorny, Emily S. 2013. How the Learning Commons Supports the Implementation of the Common Core State Standards. Universitas Central Missouri.

Putra, Yanuar S. 2016. Theoretical Review: Teori Perbedaan Generasi. Among Makarti Vol.9 No. 18.

Thorne, Laura, dkk. 2014. Learning Centres Research Project. Trends in Learning Centres and Library Developments: 2008-2013.

Truschel, Jack, dan David L. Reedy. 2009. National Survey - What is a Learning Center in the 21st Century?

\section{Website}

Bakri, Solichul H. A. 2017. Ku/tur Generasi - Z. Universitas Balikpapan:

shadibakri.uniba.ac.id/kultur-genera si-

z. (diakses 25 April 2019) 
McCrindle. 2013. Generation Z Defined Global, Visual and Digital. Australia: www.mccrindle.com.au. (diakses 30 April 2019)

Wibawanto, Hari. 2016. Generasi Z dan Pembelajaran di Pendidikan Tinggi. Bandung event.elearning.it.ac.id/assets/downloa d/materi3.pdf. (diakses 23 April 2019)

Wiley Online Library. 2017. Generation Z.' Educating and Engaging the Next Generation of Students. Wiley Online Library. About Campus/ Volume 22, issue 3. (diakses 26 April 2019)

www.kbbi.web.id (diakses 19 Maret 2019) 